dependent on the dose. Low doses are anticonvulsant while higher doses decrease seizure thresholds. In children receiving clonidine for ADHD, the lowest effective dose should be employed. In those with a history of seizures and/or epileptiform EEG, clonidine should be introduced with caution and in conjunction with an antiepileptic medication.

\title{
ANTIEPILEPTIC DRUGS
}

\section{VIGABATRIN-INDUCED SEIZURES IN ANGELMAN SYNDROME}

Four children with Angelman syndrome (AS) showed worsening of seizures after introduction of vigabatrin (VGB), at the University Children's Hospital, Zurich, Switzerland. Doses were $50-100 \mathrm{mg} / \mathrm{kg} /$ day in 3 and $150 \mathrm{mg} / \mathrm{kg} / \mathrm{day}$ in 1 . Improved seizure control followed reduction in dose of VGB to $35 \mathrm{mg} / \mathrm{kg} /$ day in one child. Myoclonic, astatic, tonic-clonic, and absence seizures were exacerbated. (Kuenzle Ch, Steinlin M, Wohlrab G, Boltshauser E, Schmitt B. Adverse effects of vigabatrin in Angelman syndrome. Epilepsia Nov 1998;39:1213-1215). (Reprints: Dr Ch Kuenzle, University Children's Hospital, Steinwiesstr 75, CH-8032 Zurich, Switzerland).

COMMENT. This report suggests that vigabatrin is contraindicated in children with Angelman syndrome and epilepsy, irrespective of the seizure type. Previous reports have found myoclonic seizures and atypical absences aggravated, but in the largest series, only $10 \%$ of epilepsies were exacerbated by VGB. Reasons for the unusual adverse effects of VGB in Angelman syndrome are undetermined.

\section{RECTAL DIAZEPAM FOR REPETITIVE SEIZURES}

The effectiveness and safety of a single-dose Diastat (diazepam rectal gel) for treating clusters of acute repetitive seizures in a nonmedical setting by caregivers was evaluated by a multicenter, double-blind study at Oregon Health Sciences University and 28 other centers. Median seizure frequency in children aged 2 years or older was significantly reduced by Diastat compared to placebo, and a greater number of Diastat patients were seizure free post-treatment $(55 \% \mathrm{cf}$ $34 \%$ ). Somnolence was the most common adverse effect. Only 3 of 56 receiving Diastat required additional emergency treatment compared to 7 of 58 in the placebo group. (Cereghino JJ, Mitchell WG, Murphy J, et al, and the North American Diastat Study Group. Treating repetitive seizures with a rectal diazepam formulation. A randomized study. Neurology Nov 1998;51:1274-1282). (Reprints: Dr JJ Cereghino, Oregon Health Sciences University, 3181 SW Sam Jackson Park Road, CDW3, Portland, OR 97201).

COMMENT. A single rectal dose of Diastat administered by a nonprofessional caregiver in a home environment is an effective and safe method of reducing seizure recurrence in children with clusters of acute repetitive seizures. The need for emergency medical treatment is often avoided, and family life is less disruptive. Respiratory depression, a safety concern after IV diazepam, was not observed after rectal Diastat.

\section{GABAPENTIN MONOTHERAPY FOR PARTIAL SEIZURES}

A randomized double-blind trial of gabapentin monotherapy in patients with newly diagnosed partial epilepsy was conducted by an international study group. Gabapentin in 74 patients in each of 3 dosage groups $(300,900$, or 1800 $\mathrm{mg} / \mathrm{day})$ was compared to open-label carbamazepine in 74 patients $(600 \mathrm{mg} / \mathrm{day})$ 
in a 24-week trial. Time to exit the study because of seizure recurrence ( 3 partial, 1 generalized tonic-clonic, or status) or adverse events was longer for patients taking gabapentin in doses of 900 or $1800 \mathrm{mg} /$ day than $300 \mathrm{mg} /$ day. Withdrawal rate was similar for carbamazepine and $1800 \mathrm{mg} /$ day gabapentin $(54 \%$ versus $57 \%$ ) but lower for gabapentin $900 \mathrm{mg} /$ day (44\%). After day 30, the $900 \mathrm{mg} /$ day group had the highest number of patients remaining in the study. Adverse events were more frequent in carbamazepine-treated patients $(84 \%)$ than in those receiving gabapentin (60\%). Rash occurred with $12 \%$ of carbamazepine and only $1 \%$ of gabapentin-treated patients. (Chadwick DW, Anhut H, Greiner MJ et al. A double-blind trial of gabapentin monotherapy for newly diagnosed partial seizures. Neurology Nov 1998;51:1282-1288). Reprints: Jeannine Alexander, Parke-Davis Pharmaceutic Research, 2800 Plymouth Rd, Ann Arbor, MI 48105).

COMMENT. Gabapentin in doses of 900 or $1800 \mathrm{mg} /$ day is an effective and relatively safe monotherapy for newly diagnosed partial epilepsy. The low incidence of skin rash and the lack of interaction with other antiepileptic drugs offer advantages over carbamazepine.

\section{METABOLIC DISORDERS}

\section{LEUKOTRIENE C4-SYNTHESIS DEFICIENCY}

A leukotriene C4-synthesis deficiency, a new inborn error of eicosanoid metabolism characterized by hypotonia, microcephaly, failure to thrive, and retarded development, is described in an infant who died aged 6 months after a rapidly progressive course at the University of Heidelberg, Germany. Concentrations of cysteinyl leukotriene LTC4 and its metabolites could not be detected in the CSF, plasma and urine, and could not be synthesised in stimulated monocytes or platelets, suggesting a deficiency of LTC4 synthase. Defective LTC4 synthesis was the presumed underlying basis for the fatal developmental syndrome. (Mayatepek E, Flock B. Leukotriene C4-synthesis deficiency: a new inborn error of metabolism linked to a fatal developmental syndrome. Lancet Nov 7, 1998;352:1514-1517). (Respond: Dr E Mayatepek, Children's Hospital, University of Heidelberg, Im Neuenhelmer Feld 150, 69120 Germany).

COMMENT. Cysteinyl leukotrienes are lipid mediators derived from arachidonic acid that have effects on vascular permeability, smooth-muscle tone, and mucus secretion. They cause bronchoconstriction, and antileukotriene drugs are now available for treatment of asthma. In addition to their role in allergic and inflammatory disorders, they are synthesized by brain tissue, concentrate in the hypothalamus, choroid plexus and CSF, and act as modulators of central nervous activity. They also affect neuroendocrine function. Leukotriene analysis of CSF should be performed in infants who have progressive neonatal neurologic deficits and consanguineous parents. Morris AAM and Rodger IW provide a helpful commentary on leukotienes and the brain (Lancet Nov 7, 1998;352:14871488).

\section{PEROXISOMAL DISORDERS DIAGNOSIS}

The clinical manifestations of 27 patients affected with peroxisomal disorders and seen between 1982 and 1997 are described from the Hopital NeckerEnfants Malades, Paris, and other centers. Zellweger syndrome, neonatal adrenoleukodystrophy, or infantile Refsum disease occurred in 20 cases. One had rhizomelic chondrodysplasia punctata, and 1 had classical Refsum disease. The 